\title{
Molecular Dynamics Analysis of SiC Single Crystal Materials
}

\author{
Wei Li \\ College of Physics and Electronic Information, Baicheng Teachers College, 137000, China
}

\begin{abstract}
SiC}$ is modeled as a new generation of semiconductor materials because of its excellent properties. The $6 \mathrm{H}-$ $\mathrm{SiC}$ is modeled by Materials Studio. The band and state density of $6 \mathrm{H}-\mathrm{SiC}$ are analyzed. In addition, $6 \mathrm{H}-\mathrm{SiC}$ Substrate, the AL element doping, from the microscopic mechanism, analyzed the $6 \mathrm{H}-\mathrm{SiC}$ semiconductor conductivity.
\end{abstract}

\section{Introduction}

$\mathrm{SiC}$ is a Group IV-IV semiconductor material. Because $\mathrm{SiC}$ has excellent properties such as large forbidden band width, high electron mobility and high thermal conductivity, it is an excellent semiconductor material for manufacturing high-power, high-frequency, hightemperature, anti-irradiation devices and The ideal material for optoelectronic integrated devices. $\mathrm{SiC}$ has a variety of homologous isomers, and its typical crystal structure is divided into two categories: one is a hexagonal or rhombic structure, with a large periodic structure such as $4 \mathrm{H}, 6 \mathrm{H}, 15 \mathrm{R}$, etc., usually called $\alpha-\mathrm{SiC}$ and the other is The cubic form of the zinc blende structure, commonly referred to as $\beta$-SiC. The general characteristics of various crystal forms of $\mathrm{SiC}$ are shown in Table 1:

Table 1. Characteristics of various $\mathrm{SiC}$ crystal forms

\begin{tabular}{|c|c|c|}
\hline Performance & $3 \mathrm{C}-\mathrm{SiC}$ & $2 \mathrm{H}-\mathrm{SiC}$ \\
\hline Molar mass $(\mathrm{g} *$ mol- 1$)$ & 40.097 & 40.097 \\
\hline $\operatorname{Density}(\mathrm{g} * \mathrm{~cm}-3)$ & 3.22 & 3.22 \\
\hline Melting point $\left({ }^{\circ} \mathrm{C}\right)$ & 2730 & 2730 \\
\hline Lattice constant $(\mathrm{nm})$ & 0.43595 & 0.3080 \\
\hline Dielectric constant & 9.72 & 10.32 \\
\hline \multicolumn{3}{|l|}{$\begin{array}{l}\text { Breakdown electric field } \\
(\mathrm{V} * \mathrm{~cm}-1)\end{array}$} \\
\hline $\begin{array}{l}\text { Electron mobility } \\
(\mathrm{cm} 2 * \mathrm{~V}-1 * \mathrm{~s}-1)\end{array}$ & 1000 & \\
\hline $\begin{array}{c}\text { Hole mobility } \\
(\mathrm{cm} 2 * \mathrm{~V}-1 * \mathrm{~s}-1)\end{array}$ & & 40 \\
\hline $\begin{array}{l}\text { Thermal conductivity } \\
(\mathrm{W} * \mathrm{~cm}-1 * \mathrm{~K}-1)\end{array}$ & 4.9 & 4. 9 \\
\hline $\begin{array}{l}\text { Electron saturation drift } \\
\text { speed }\left(\mathrm{cm}^{*} \mathrm{~s}-1\right)\end{array}$ & 2. $0^{*} 10^{7}$ & \\
\hline
\end{tabular}

In order to facilitate the comparison, we compare the performance of other natural forms of SIC in the form of a table. The comparison items we used include Breakdown electric field, Electron mobility, Hole
mobility,Thermal conductivity and Electron saturation drift speed. The data of the comparison is shown in Table 2 .

Table 2. Characteristics of various $\mathrm{SiC}$ crystal forms

\begin{tabular}{|c|c|c|}
\hline Performance & $4 \mathrm{H}-\mathrm{SiC}$ & $6 \mathrm{H}-\mathrm{SiC}$ \\
\hline Molar mass $(\mathrm{g} *$ mol- 1$)$ & 40.097 & 40.097 \\
\hline Density $(\mathrm{g} * \mathrm{~cm}-3)$ & 3.26 & 3.03 \\
\hline Melting point $\left({ }^{\circ} \mathrm{C}\right)$ & 2730 & 2730 \\
\hline Lattice constant $(\mathrm{nm})$ & 0.3073 & 0.3073 \\
\hline Dielectric constant & 9.7 & 9.7 \\
\hline $\begin{array}{c}\text { Breakdown electric field } \\
(\mathrm{V} * \mathrm{~cm}-1)\end{array}$ & $2.2 * 106$ & $2.4 * 106$ \\
\hline $\begin{array}{c}\text { Electron mobility } \\
(\mathrm{cm} 2 * \mathrm{~V}-1 * \mathrm{~s}-1)\end{array}$ & 1020 & 600 \\
\hline $\begin{array}{c}\text { Hole mobility } \\
(\mathrm{cm} 2 * \mathrm{~V}-1 * \mathrm{~s}-1)\end{array}$ & 120 & 40 \\
\hline $\begin{array}{c}\text { Thermal conductivity } \\
\left(\mathrm{W} * \mathrm{~cm}-1{ }^{* \mathrm{~K}-1)}\right.\end{array}$ & 4.9 & 4.9 \\
\hline $\begin{array}{c}\text { Electron saturation drift } \\
\text { speed ( cm * s- } 1)\end{array}$ & $2.0 * 10^{7}$ & $2.0 * 10^{7}$ \\
\hline
\end{tabular}

\section{Calculation methods and discussion}

\subsection{Molecular Dynamics Analysis of Intrinsic 6H- SiC Crystals}

Materials Studio is a simulation software specially developed for materials science. The CASTEP module in Materials Studio uses advanced quantum mechanical algorithms. Therefore, Materials Studio is widely used in the electronic structure (energy band and density of states) of crystalline materials. Analysis, calculation of surface remodeling and its properties, lattice defects (grain boundaries, dislocations, etc.), charge density, semiconductor doping, etc. First, create a $6 \mathrm{H}-\mathrm{SiC}$ model in the Materials Studio window, as shown in Figure 1: 


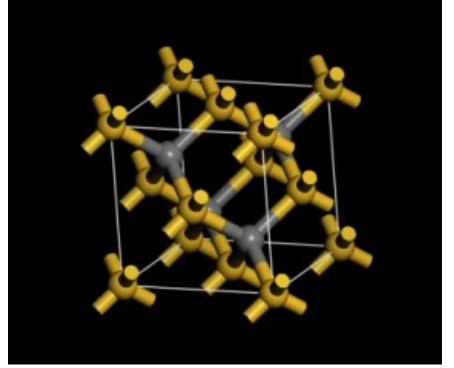

Figure 1. 6H-SiC model built in Materials Studio

First, the energy band diagram of the intrinsic $6 \mathrm{H}-\mathrm{SiC}$ crystal is analyzed. The energy band diagram is shown in Figure 2:

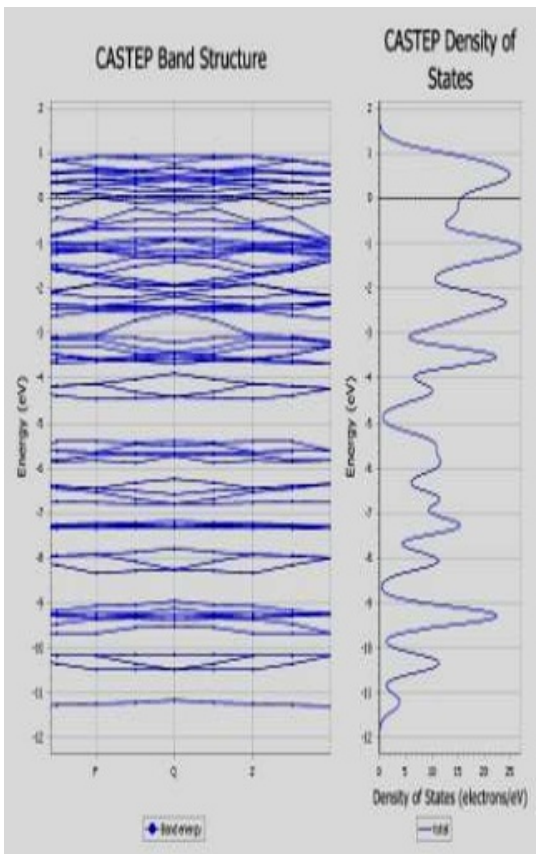

Figure 2. Energy band diagram of $6 \mathrm{H}-\mathrm{SiC}$

The energy band diagram analysis of $6 \mathrm{H}-\mathrm{SiC}$ shows that the forbidden band width of $6 \mathrm{H}-\mathrm{SiC}$ is calculated to be $2.5 \mathrm{eV}$, which is slightly narrower than the experimentally measured forbidden band width. The main reason is that the generalized gradient approximation (GGA) is used. When the 3D energy overestimation of $6 \mathrm{H}-\mathrm{SiC}$ is caused, the energy overestimation tends to increase the $2 p$ interaction between $\mathrm{Si}$ and $\mathrm{C}$, which leads to the increase of the valence band bandwidth of $6 \mathrm{H}-\mathrm{SiC}$. low. However, the overall trend change of the $6 \mathrm{H}-\mathrm{SiC}$ energy band diagram is consistent with the experimental values. It can be seen that the $6 \mathrm{H}-\mathrm{SiC}$ band diagram calculated by the first principle, ie, the density functional theory can be used as the basis for analyzing the microscopic properties of $6 \mathrm{H}-\mathrm{SiC}$. It can also be seen from the energy band diagram that the lowest point of the conduction band and the highest point of the valence band are at the same symmetry point, which means that $6 \mathrm{H}-$ $\mathrm{SiC}$ is an excellent direct forbidden semiconductor material, and Figure 3 is $6 \mathrm{H}$. -State density distribution map of $\mathrm{SiC}$ :

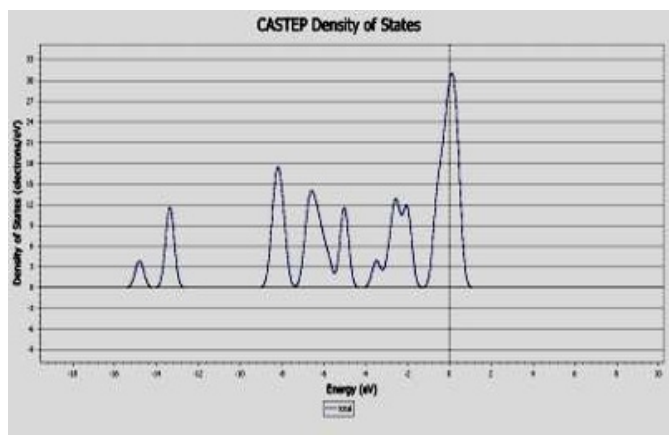

Figure 3. State density distribution of $6 \mathrm{H}-\mathrm{SiC}$

As can be seen from the analysis of Fig. 3, the density of states increases at the Fermi level, which indicates that the range of the Fermi level entering the valence band is deep. The N-type of $6 \mathrm{H}-\mathrm{SiC}$ tends to be obvious. In Figure 3 , the peak density of the p-electron of $6 \mathrm{H}-\mathrm{SiC}$ is 25 , and the peak density of the p-electron of $6 \mathrm{H}-\mathrm{SiC}$ increases to 32 , which means $6 \mathrm{H}-\mathrm{SiC}$. The phenomenon that the number of carriers does not match, the number of electrons is more than the number of holes, and then try to dope +3 valence elements, and judge whether the stability of the system and the performance of $6 \mathrm{H}-\mathrm{SiC}$ performance.

\subsection{Performance analysis after SiC doping}

According to semiconductor theory, the electrical conductivity of a semiconductor material increases, which causes an increase in the dielectric constant. At the same time, it will also bring about an increase in dielectric loss and leakage. According to the principle of first matching after loss, $6 \mathrm{H}-\mathrm{SiC}$ is used as the substrate material, and $\mathrm{Al}$ element is doped. FIG. 4 is a model diagram of doping $\mathrm{Al}$ element in $6 \mathrm{H}-\mathrm{SiC}$ substrate:

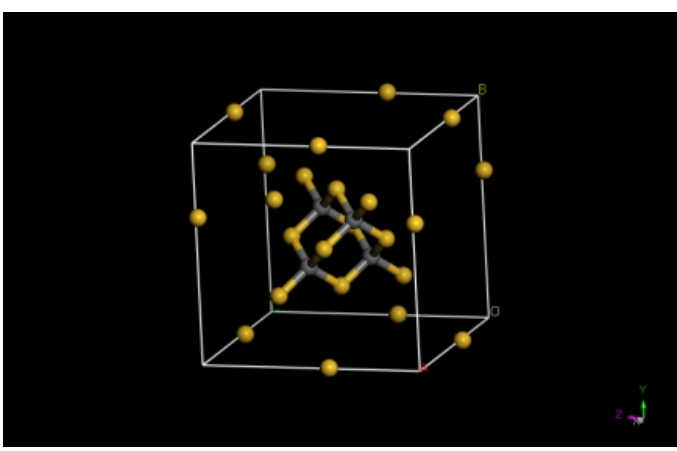

Figure 4. Doped $\mathrm{Al}$ in a $6 \mathrm{H}-\mathrm{SiC}$ substrate

Energy band analysis of $6 \mathrm{H}-\mathrm{SiC}$ doped with $\mathrm{Al}$ was carried out using the CASTEP module of Materials Studio. The energy band diagram is shown in Figure 5: 


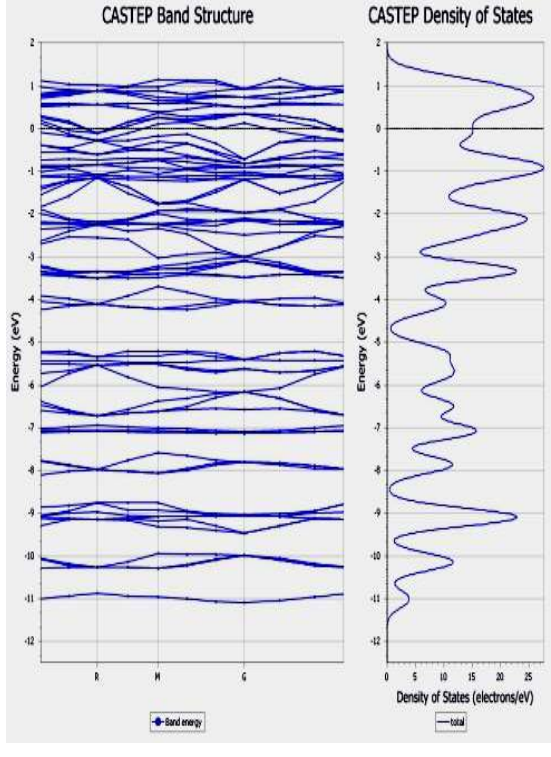

Figure 5. 6H-SiC band diagram of Al-doped element

The energy band diagram shown in Fig. 5 shows that after doping, the impurity level appears in the valence band, and the forbidden band width becomes wider. It can be seen from the analysis that the Fermi level has begun to enter the valence band. This means that intrinsic semiconductors have a tendency to shift toward p-type semiconductors. From the energy point of view, the energy of the system has improved. From the point of view of electronic structure, in the impurity semiconductor, Ef enters the valence band, and the quantum state near the end of the valence band terminus has been substantially occupied by the hole, which means that the doping level is high. Next, we analyze the state density map of the doped $\mathrm{Al}$ element. The density distribution of the $6 \mathrm{H}-\mathrm{SiC}$ state doped with $\mathrm{Al}$ is shown in Figure 6:

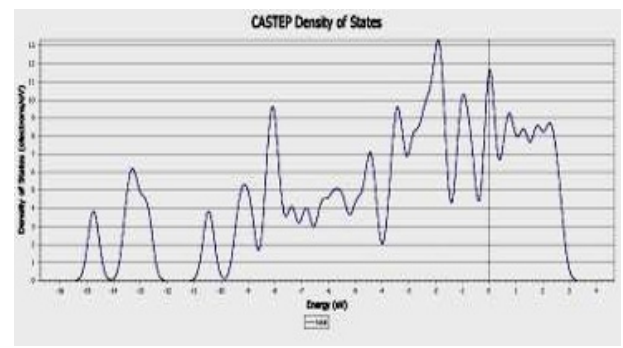

Figure 6. Density distribution of $6 \mathrm{H}-\mathrm{SiC}$ state doped with $\mathrm{Al}$

It can be seen from the analysis of Fig. 6 that the doping composition has a certain influence on the electrical conductivity of $6 \mathrm{H}-\mathrm{SiC}$. We use the electrons of the $3 \mathrm{~d}, 4 \mathrm{~s}$ and $4 \mathrm{p}$ states of the $\mathrm{Al}$ atom as valence electrons, and the $2 \mathrm{~s}$ and $2 \mathrm{p}$ electrons of $6 \mathrm{H}-\mathrm{SiC}$ as valence electrons for comparative analysis. Since $6 \mathrm{H}-\mathrm{SiC}$ crystals have certain lattice defects, they are Multiple donor states are generated on the density distribution map, while $\mathrm{Al}$ is easier to compensate for the $\mathrm{N}$ impurity acceptor for the preparation of p-type doped $6 \mathrm{H}-\mathrm{SiC}$, so $\mathrm{Al}$ is a better dopant.

\section{Calculation}

Crystal growth can be considered to be caused by stable electrical oscillation, assuming that the growth of the container length is $l$, voltage is $v_{0} \sin \omega t$, the problem can be described as:

$$
\begin{gathered}
E_{t t}-a^{2} E_{X X}=0 \\
\left.E\right|_{X=0}=v_{0} \sin \omega t \\
\left.E\right|_{X=l}=0
\end{gathered}
$$

Because the use of complex numbers to calculate more convenient, Therefore, the boundary condition $v_{0} \sin \omega t$ is rewritten as $v_{0} e^{i \omega t}$, that is, the imaginary part of the complex number $\operatorname{Im}\left(v_{0} \sin \omega t\right)$. When the calculation is completed, the imaginary part of the result is the solution of the equation. Since the steady oscillation is caused by the AC power supply, the cycle is the same as the AC power cycle:

$$
E(x, t)=X(x) e^{i \omega t}
$$

Substituting equation (4) into the ordinary differential equation of $X$ yields: $X^{\prime \prime}+(\omega / a)^{2} X=0$

Solving the ordinary differential equation of $\mathrm{X}$ : $X(x)=A e^{\frac{i \omega x}{a}}+B e^{-\frac{i \omega x}{a}}$, and so:

$$
E(x, t)=\left[A e^{\frac{i \omega x}{a}}+B e^{-\frac{i \omega x}{a}}\right] e^{i \omega t}
$$

Substituting equation (5) into equation (2) yields:

$$
[A+B] e^{i \omega t}=v_{0} \sin \omega t
$$

Substituting equation (5) into equation (3) yields:

$$
\left[A e^{\frac{i \omega l}{a}}+B e^{-\frac{i \omega l}{a}}\right]=0
$$

The imaginary part of expression $E(x, t)$ is the final solution of the equation:

$$
E(x, t)=v_{0} \frac{\sin \frac{\omega(l-x)}{a} \sin \omega t}{\sin \left(\frac{\omega l}{a}\right)}
$$

Assuming that there is an initial perturbation in region, the region affected by this disturbance can be described as a sphere with the center of $\mathrm{M}$ as the radius and the sphere as the inner envelope and the outer The surface of the surface is the area where the fluctuation has been conveyed, and the outer envelope is the area where the 
disturbance has not yet been conveyed. The above process is described by the following equation:

$$
E_{t t}-a^{2} \Delta E=0
$$

The equation is implemented by separating the variable method:

$$
E(r, t)=T(t) v(r)
$$

Equation (10) is substituted into equation(9): $\frac{T^{\prime \prime}}{a^{2} T}=\frac{\Delta v}{v}$

Equation on the left is a function of $\mathrm{t}$, the right side of the equation is a function of $r$, the equation to be established, must be equal to the same constant, the constant as $-k^{2}$, then get two equations:

$$
\begin{gathered}
T^{\prime \prime}+k^{2} a^{2} T=0 \\
\Delta v+k^{2} v=0
\end{gathered}
$$

The solution of Eq. (11) is:

$$
\left\{\begin{array}{l}
T(t)=C \cos k a t+D \sin k a t \quad(k \neq 0) \\
T(t)=C+D t \quad(k=0)
\end{array}\right.
$$

In the spherical coordinate system, the solution of Eq. (12) is:

$$
\frac{1}{r^{2}} \frac{\partial}{\partial r}\left(\frac{r^{2} \partial v}{\partial r}\right)+\frac{1}{r^{2} \sin ^{2} \theta} \frac{\partial^{2} v}{\partial \varphi^{2}}+k^{2} v=0
$$

Separate variables on variable V:

$$
v(\rho, \varphi, z)=R(\rho) Y(\theta, \varphi)
$$

Substituting equation (13), Equation (13) is divided by $\left(\frac{r^{2}}{R Y}\right)$ at both ends:

$$
\frac{1}{R} \frac{d}{d r}\left(r^{2} \frac{d R}{d r}\right)+k^{2} r^{2}=\frac{-1}{Y \sin \theta} \frac{\partial}{\partial \theta}\left(\sin \theta \frac{\partial Y}{\partial \theta}\right)-\frac{\partial^{2} Y}{\partial \varphi^{2}}
$$

The left side of the equation is a function of $r$, and the right side of the equation is a function of $\theta$ and $\varphi$. If the equation holds, the equation needs to be equal to a constant Let the constant be $l(l+1)$ :

$$
\begin{gathered}
\frac{1}{R} \frac{d}{d r}\left(r^{2} \frac{d R}{d r}\right)=\frac{-1}{Y \sin \theta} \frac{\partial}{\partial \theta}\left(\sin \theta \frac{\partial Y}{\partial \theta}\right) \\
-\frac{R}{Y \sin ^{2} \theta} \frac{\partial^{2} Y}{\partial \varphi^{2}}=l(l+1)
\end{gathered}
$$

Get two equations :

$$
\frac{\partial}{\partial \theta}\left(\sin \theta \frac{\partial Y}{\partial \theta}\right)+\frac{\partial^{2} Y}{\partial \varphi^{2}}+l(l+1) Y=0
$$

Equation (14) is not a standard Bessel equation, and the equation (14)is transformed so that: $x=k r$, Substituting equation (14)

$$
x^{2} R^{\prime \prime}+2 x R^{\prime}+\left[x^{2}-l(l+1)\right] R=0
$$

Let $R=\frac{\omega}{\sqrt{x}}$, substitute equation (14)

$$
x^{2} \omega^{\prime \prime}+x \omega^{\prime}+\left[x^{2}-\left(l+\frac{1}{2}\right)^{2}\right] \omega=0
$$

$v=\left(l+\frac{1}{2}\right)$, substitute equation (14)

$$
x^{2} y^{\prime \prime}+x y^{\prime}+\left(x^{2}-v^{2}\right) y=0
$$

$x_{0}=0$ is the first order pole of $p(x)=(1 / x)$, the second order pole of $q(x)=\left(1-v^{2} / x^{2}\right)$, so: $x_{0}=0$ is the regular singularity of the equation Determine the equation: $s(s-1)+s-v^{2}=0$

Determine the two roots of the equation:

$$
\begin{gathered}
s_{1}=v, s_{2}=-v ; \quad\left(s_{1}-s_{2}=2 \text { or } \mathrm{v} \text { is an integer }\right) \\
y(x)=a_{0} x^{S}+a_{1} x^{S+1} \ldots+a_{K} x^{S+K} \ldots\left(a_{0} \neq 0\right)
\end{gathered}
$$

The recursive formula for the coefficients is:

$$
\left[(s+k)^{2}-v^{2}\right] a_{k}+a_{k-2}=0
$$

among:

$$
a_{k}=\frac{-a_{k-2}}{(s+k)^{2}-v^{2}}=\frac{-a_{k-2}}{(s+k+v)(s+k-v)-v^{2}}
$$

The general solution of the equation is:

$$
y(x)=\sum_{k=0}^{\infty} \frac{(-1)^{k}}{\Gamma(v+k+1)}\left(\frac{x}{2}\right)^{v+2 k}+\sum_{k=0}^{\infty} \frac{(-1)^{k}}{\Gamma(-v+k+1)}\left(\frac{x}{2}\right)^{-v+2 k}
$$

The calculation is in good agreement with the experimental results, which proves that our mathematical model is correct.

\section{Conclusion}

The $6 \mathrm{H}-\mathrm{SiC}$ crystal was modeled by Materials Studio, and Al-doped with $6 \mathrm{H}-\mathrm{SiC}$. Then the $6 \mathrm{H}-\mathrm{SiC}$ band diagram and density map were analyzed using the CASTEP module of Materials Studio. In order to facilitate the comparison, we compare the performance of other natural forms of SIC in the form of a table. The comparison items we used includeBreakdown electric field, Electron mobility, Hole mobility, Thermal conductivity and Electron saturation drift speed. The data of the comparison is shown in article. The following conclusions were obtained: 
(1) $6 \mathrm{H}-\mathrm{SiC}$ is a wide bandgap semiconductor material with a band gap of $2.2 \mathrm{eV}$, so it can be used as an LED luminescent material.

(2) $6 \mathrm{H}-\mathrm{Si}$ has a variety of crystal forms, and the crystals of different forms have different forbidden bands. However, regardless of the crystal form, the forbidden band width is larger than that of common semiconductor materials such as silicon and germanium, so $6 \mathrm{H}-\mathrm{SiC}$ is used as Semiconductor materials can reduce the leakage current of semiconductor devices, and $6 \mathrm{H}-\mathrm{SiC}$ also has high temperature resistance, so it can replace semiconductor materials such as $\mathrm{Si}$ and $\mathrm{Ge}$ under high temperature conditions.

(3) Doping $\mathrm{Al}$ with $6 \mathrm{H}-\mathrm{SiC}$ as a substrate can effectively change the nonlinear conductivity of $6 \mathrm{H}-\mathrm{SiC}$, which has a certain effect on improving semiconductor characteristics. In addition, the adsorption of metal impurities such as $\mathrm{Ti}, \mathrm{Fe}, \mathrm{Ca}, \mathrm{Mg}$ on the surface of $6 \mathrm{H}$ $\mathrm{SiC}$ can also effectively change the conductivity of $6 \mathrm{H}$ $\mathrm{SiC}$ crystal.

\section{References}

1. Zhang Yi-Men, Tang Xiao-Yan, Guo Hui. Chinese Physics $B$ The fabrication and characterization of $4 \mathrm{H}-\mathrm{SiC}$ power UMOSFETs (2013)

2. B. Y. Thakore, S. G. Khambholja, A. Y. Vahora, N. K. Bhatt, A. R. Jani. Thermodynamic properties of 3C SiC[. Chinese Physics B. (2013)

3. A. Y. Vahora, N. K. Bhatt, A. R. Jani. Thermodynamic properties of $3 \mathrm{C}-\mathrm{SiC}$. Khambholja, Chinese Physics B (2013)

4. Tolga Tekin, Klaus Lang, Ha-DuongNgo. Microsystem Technologies. Measurement of Young's modulus and residual stress of thin SiC layers for MEMS high temperature applications. Oliver Pabst, Michael Schiffer, Ernst Obermeier, (2012) 